\title{
Management of ureteropelvic junction obstruction in horseshoe kidneys by an assortment of laparoscopic options
}

\author{
Pejman Shadpour, H. Habib Akhyari, Robab Maghsoudi, Masoud Etemadian \\ Hasheminejad Kidney Center (HKC), Hospital Management Research Center (HMRC), Iran University of Medical Sciences (IUMS), Tehran, Islamic Republic of Iran
}

Cite as: Can Urol Assoc J 2015;9(11-12):E775-9. http://dx.doi.org/10.5489/cuaj.3111 Published online November 4, 2015.

\section{Abstract}

Introduction: We report our experience with laparoscopic management of ureteropelvic junction obstruction in horseshoe kidneys. Methods: Between February 2004 and March 2014, 15 patients with horseshoe kidneys and symptomatic ureteropelvic junction obstruction underwent laparoscopic management at our national referral centre. Depending on the anatomy and presence of obtrusive vessels or isthmus, we performed either dismembered, Scardino or Foley YV pyeloplasty, or Hellstrom vessel transposition. Patients were initially evaluated by ultrasonography, then diuretic scintiscan at 4 to 6 months, and followed by yearly clinical and sonographic exams.

Results: This study included 11 male and 4 female patients between the ages of 4 to 51 year (average 17.7). The left kidney was involved in 12 patients (80\%). Operation time was 129 minutes (range: 90-186), and patients were discharged within 2.8 days (range: $1-6)$. Although 8 (53.3\%) patients had crossing vessels, of which 6 required transposing, the Hellstrom technique was solely used in 3 cases, of which notably 1 case failed to resolve and required laparoscopic Hynes within the next year. Eight cases underwent dismembered pyeloplasty, 2 Foley YV, 1 Scardino flap and 1 required isthmectomy and vessel suspension. At the mean follow-up of 60 (range: 18-120) months, the overall success rate was $93.3 \%$.

Conclusions: To our knowledge, this represents the largest report on laparoscopic pyeloplasty for horseshoe kidneys, providing the longest follow-up. Our findings confirm prior reports supporting laparoscopy and furthermore show that despite the prevalence of crossing vessels, transposition alone is seldom sufficient.

\section{Introduction}

Horseshoe kidneys are the most common renal fusion anomalies, estimated to occur in $0.25 \%$ of the population. They are more common in males, at a 2:1-ratio. Horseshoe kid- neys are frequently associated with other congenital anomalies and ureteropelvic junction obstruction (UPJO). ${ }^{1}$ The following factors may contribute to UPJO in horseshoe kidneys: anomalous vascular supply to the kidney, high insertion of the ureter into the renal pelvis, its abnormal course over the isthmus, and its intrinsic pathogenesis. ${ }^{1}$ Laparoscopic and robotic pyeloplasty have been successful in treating horseshoe kidneys with acceptable functional results, although study subjects are limited..$^{2-4}$ Endopyelotomy is another minimally invasive option, but has displayed inferior outcome. ${ }^{5}$ Our study followed patients beyond the initial postoperative period - our results can help minimally invasive urologists choose the most appropriate laparoscopic reconstruction technique for each patient.

\section{Methods}

Between February 2004 and March 2014, 15 patients with horseshoe kidneys and symptomatic UPJO underwent laparoscopic management at our national referral centre. After detecting hydronephrosis and an isthmus on sonography, we evaluated the UPJO by a diuretic diethylene triamine penta acetic acid (DTPA) renal scan. Patients with significant UPJO (defined as prolonged evacuation T1/2 on diuretic renogram beyond 20 minutes into the infusion of $1 \mathrm{mg} / \mathrm{kg}$ furosemide) were managed by transperitoneal laparoscopy. We have previously detailed our laparoscopic pyeloplasty technique, including the now standard transmesocolic approach to the left kidney. ${ }^{6}$

Upon releasing the ureter and ureteropelvic junction from adjacent vascular structures, we observed the pelvis for distension intraoperatively over 10 minutes of induced diuresis before confirming the obstructive role of crossing vessels. When implicated, we divided the crossing veins and relocated the mobilized artery cephalad into a plication of renal pelvis according to the Hellstrom technique. Grossly normal peristalsis across the junction, and rapid and sustained detumescence of the pelvis were exclusively taken to 
indicate that this measure alone may have sufficed. In only 1 instance, the ureter would drop into a "memory" kink, but otherwise normal peristalsis, for which a $4.8 \mathrm{Fr}$ double J stent was additionally inserted via ureteroscopy.

In all other cases, concomitant intrinsic UPJO was evident and classic reconstruction was done. Based on individual anatomic circumstances, we used the Anderson-Hynes dismembered pyeloplasty for short stenotic segments, Foley YV for high insertion ureters, and the Scardino vertical flap pyeloplasty for a large extra-renal pelvis. Isthmectomy and lateralized pexing of the lower pole to the psoas was only performed if the isthmus was visibly impeding the outflow.

All double J stents were removed 6 weeks postoperatively. Patients were initially evaluated by ultrasonography, then by diuretic scintiscan at 4 to 6 months (Table 1), followed by yearly clinical and sonographic evaluations. Success was defined as improvement of the washout curve on diuretic scintiscan, plus sustained symptomatic relief and favourable sonographic findings over the course of follow-up.

After obtaining approval from our institutional ethical committee, we reviewed the perioperative parameters, including demographics, intraoperative findings, hospital stay, complications and findings on clinical follow-up.

\section{Results}

Of the 15 patients with horseshoe kidneys with UPJO, 11 were male and 4 were female. All had unilateral UPJO, 12 patients with UPJO on the left side. Their mean age was 17.7 years (range: 4-51) (Table 2). Presenting symptoms included lateralized flank pain in 13 patients, vague abdominal pain radiating to the lower lumbar region in 2, and concurrent micro hematuria in another 2. Preoperative diuretic renogram results invariably displayed an obstructive washout curve, with an average 70-minute T1/2 (range: 40 to over 180). Differential renal function averaged $45.7 \%$ on the involved side.

Eight kidneys (53.3\%) had anterior crossing vessels, of which 2 were only released and 6 required to be transposed. The surgeon subjectively judged Hellstrom suspension alone as sufficient for decompression in only three. Notably, one of the latter patients (the one furnished with

\begin{tabular}{|c|c|c|}
\hline Postoperative DTPA & Symptoms & Result \\
\hline $\mathrm{T} 1 / 2<20 \mathrm{~min}$ & Resolved & Success \\
\hline \multirow{2}{*}{$20<\mathrm{T} 1 / 2<40 \mathrm{~min}$} & Success & Success \\
\hline & Failure & Failure \\
\hline $\mathrm{T} 1 / 2>40 \mathrm{~min}$ & Any & Failure \\
\hline
\end{tabular}

*Using the F+20 protocol; UPJO: ureteropelvic junction obstruction; DTPA: diethylene triamine penta acetic acid. a double $\mathrm{J}$ to straighten the memory-kinking effect of his redundant freed ureter) worsened on the 4th month nuclear scan, and became progressively symptomatic. His procedure was deemed unsuccessful and he underwent a second laparoscopic procedure at month 7 postoperatively with an Anderson Hynes dismembered pyeloplasty. After surgery, both symptoms and scan confirmed durable resolution of the obstruction.

The 24-year-old male displayed a desmoplastic process limited to the isthmus proper and required intra peritonealization of the upper ureter after isthmectomy and vessel suspension. Two patients required concomitant removal of renal stones. In the 51-year-old male, the removal of all 26 stones from the middle and lower calyces was greatly facilitated by the wide exposure created in preparation for the Scardino flap.

Skin to trochar laparoscopy time averaged 129 minutes (range: 90-186). There were no intraoperative complications, but an adult female was required to remain in hospital until her febrile urinary tract infection resolved on parenteral antibiotics. This was recorded as a Clavien II event, and 2 other patients were kept for an extra day for what proved to be a non-infectious febrile episode (Clavien I). All other patients with reconstruction and anastomosis of the urinary tract were discharged after removal of their urethral catheter and drain on postoperative day 3. Patients managed by vessel transposition alone were generally allowed to leave the hospital the next morning. Consequently the mean hospital stay was 2.8 days. With an average follow-up of 60 months (range: 18-120), the long-term success rate was $93.3 \%$ (Table 2 ).

\section{Discussion}

Classic literature on the surgical management of UPJO in horseshoe kidneys includes the standard open dismembered pyeloplasty with isthmectomy and nephropexy of the ipsilateral kidney. ${ }^{7}$ More contemporary literature maintains that management and surgical indications for UPJO in patients with horseshoe kidney follow the same guidelines as for any pyeloplasty, raising the formerly cited inferior success rates of $55 \%$ to $80 \%$ in horseshoe kidneys to $90 \%$ to $100 \%{ }^{7}$

Laparoscopic pyeloplasty, introduced by Schussler in 1993, is easier in horseshoe kidneys where the pelvis and ureteropelvic junction are located anteriorly, hence readily available to transperitoneal laparoscopy. ${ }^{2-4,8}$ The total number of laparoscopic pyeloplasties in horseshoe kidneys and their follow-up are too limited to derive any specific guidelines. Recently Spencer and colleagues ${ }^{9}$ reported satisfactory results on 1 year follow-up of 2 patients aged 28 and 35 years without any crossing vessels using robotic-assisted laparoscopic dismembered pyeloplasty. The mean operation time and hospital stay were 140 minutes and 2 days, respec- 


\begin{tabular}{|c|c|c|c|c|c|c|c|c|c|c|c|c|}
\hline Case & Age & Side & Sex & $\begin{array}{l}\text { Preop } \\
\text { T } 1 / 2 \\
(\min )\end{array}$ & $\begin{array}{l}\text { Preop } \\
\text { diff. } \\
\text { func. } \%\end{array}$ & $\begin{array}{l}\text { Crossing } \\
\text { elements }\end{array}$ & $\begin{array}{c}\text { OR } \\
\text { time } \\
\text { (min) }\end{array}$ & $\begin{array}{l}\text { Hospital } \\
\text { stay } \\
\text { (days) }\end{array}$ & $\begin{array}{l}\text { Postop } \\
\text { T } 1 / 2 \\
\text { (min) }\end{array}$ & $\begin{array}{l}\text { Follow-up } \\
\text { (months) }\end{array}$ & Laparoscopic technique & $\begin{array}{l}\text { Clinical } \\
\text { result }\end{array}$ \\
\hline 1 & 31 & L & $\mathrm{F}$ & 60 & 40 & Yes (Lp) & 134 & 3 & $\begin{array}{l}\mathrm{T} 1 / 2 \\
(\mathrm{~min})\end{array}$ & 108 & $\begin{array}{l}\text { Dismembered }+ \text { cephalad } \\
\text { vascular relocation }\end{array}$ & Success \\
\hline 2 & 4 & $\mathrm{~L}$ & $\mathrm{M}$ & $>180$ & 40 & No & 110 & 3 & 19 & 120 & Dismembered & Success \\
\hline 3 & 5 & L & $\mathrm{M}$ & 100 & 42 & No & 117 & 3 & 17 & 96 & Dismembered & Success \\
\hline 4 & 8 & $\mathrm{R}$ & $\mathrm{M}$ & 60 & 58 & Yes (Lp) & 132 & 3 & 18 & 72 & $\begin{array}{l}\text { Dismembered }+ \text { cephalad } \\
\quad \text { vascular relocation }\end{array}$ & Success \\
\hline 5 & 7 & $\mathrm{~L}$ & $\mathrm{M}$ & 60 & 45 & Yes (Lp) & 104 & 3 & 19 & 72 & Dismembered & Success \\
\hline 6 & 10 & $\mathrm{~L}$ & $\mathrm{M}$ & 90 & 35 & Yes (Lp) & 98 & 3 & 17 & 72 & Dismembered & Success \\
\hline 7 & 24 & L & $\mathrm{M}$ & 40 & 42 & $\begin{array}{l}\text { Yes (Lp+ } \\
\text { Isthmus) }\end{array}$ & 186 & 1 & 22 & 60 & $\begin{array}{l}\text { Hellstrom + isthmectomy } \\
+ \text { ureterolysis + ureteral } \\
\text { intraperitonealization }+\mathrm{JJ} \\
\text { insertion }\end{array}$ & Success \\
\hline 8 & 20 & L & $\mathrm{M}$ & 40 & 36 & Yes (Lp) & 98 & 1 & 30 & 60 & Hellstrom & Success \\
\hline 9 & 5 & L & $\mathrm{M}$ & 90 & 45 & No & 144 & 3 & 15 & 36 & Dismembered & Success \\
\hline 10 & 4 & L & $\mathrm{M}$ & 50 & 60 & Yes (Lp) & 90 & 2 & 18 & 60 & Hellstrom + DJ insertion & Failure \\
\hline 11 & 35 & $L$ & $\mathrm{~F}$ & 60 & 45 & No & 150 & 6 & 65 & 48 & Dismembered & Success \\
\hline 12 & 14 & $\mathrm{R}$ & $\mathrm{F}$ & 55 & 60 & No & 165 & 3 & 15 & 36 & $\begin{array}{l}\text { Foley YV pyeloplasty + } \\
\text { pyelolithotomy }\end{array}$ & Success \\
\hline 13 & 28 & $\mathrm{R}$ & $\mathrm{F}$ & 45 & 50 & No & 150 & 4 & 10 & 24 & Foley YV pyeloplasty & Success \\
\hline 14 & 19 & $\mathrm{~L}$ & $\mathrm{M}$ & 50 & 47 & Yes (Lp) & 90 & 1 & 12 & 18 & Hellstrom & Success \\
\hline 15 & 51 & $\mathrm{~L}$ & $\mathrm{M}$ & 90 & 40 & No & 173 & 3 & 28 & 18 & $\begin{array}{c}\text { Vertical flap (Scardino) }+ \\
\text { pyelolithotomy }\end{array}$ & Success \\
\hline
\end{tabular}

UPJO: ureteropelvic junction obstruction; L: left; R: right; F: female; M: male; Lp: lower pole; T1/2: 50\% evacuation time on diuretic renogram; diff. func.: differential function; OR: operation; Preop: preoperative; Postop: postoperative.

tively. Nadler and colleauges ${ }^{10}$ performed hand-assisted laparoscopic dismembered pyeloplasty and isthmectomy using the harmonic scalpel in a 36-year old female. The operation time and hospital stay were 230 minutes and 3 days, respectively. Moreover, Chammas and colleagues described robotic-assisted laparoscopic dismembered pyeloplasty in 3 patients aged 25, 43 and 66 years. Their mean operative time and hospital stay were 148 minutes and 7.6 days, respectively. All 3 patients had resolution on clinical and radiographic evaluation up to 21 months (Table 3). ${ }^{11}$

Crossing renal vessels are present in at least $40 \%$ of adults with primary UPJO. ${ }^{1}$ Highly variable anomalous blood supply to horseshoe kidneys further increases the potential for extrinsic compression of an entrapped ureter. The actual contribution of crossing vessels to obstruction is difficult to demonstrate and much less to quantify, but transperitoneal laparoscopy can provide adequate work space to disengage the ureter and vessels in anticipation of transposing the structures once indicated. Anderson-Hynes dismembered pyeloplasty is the most versatile laparoscopic procedure for UPJO even in horseshoe kidneys, as it can allow for the removal of the intrinsic obstructive segment and re-anastomosis anterior to the imposing vessels or isthmus.

In 2003 Meng and colleagues revisited the old concept originally proposed by Hellstrom in 1949, by repositioning obstructive vessels cephalad and building upon the less invasive surgical exposure made possible through laparoscopy. ${ }^{12}$ This technique has subsequently been repeated in adults and pediatric patients with satisfactory results, including recent reports. ${ }^{13}$ Where applicable, vascular relocation without pyeloplasty carries some potential benefits, including short operation time, minimal hospital stay, and obviating anastomotic complications, such as stricture, urine leak and stent removal.

In our series of 15 patients, 8 (53\%) of horseshoe kidneys patients had crossing vessels. Our larger sample size may explain why this figure is closer to the general population $(40 \%)^{1}$ than Faddegon's $7 / 9(78 \%){ }^{8}$ In $2 / 8$ patients $(25 \%)$, we left the vessels untouched, while dismembering cured the obstruction durably. In 3/8 patients (37\%), the vessels were repositioned cephalad only as an adjunct to the main corrective surgery (dismembering in two cases, and isthmectomy, nephropexy and intra-peritonealization of the ureteropelvic junction in one patient). Hellstrom suspension alone provided sufficient relief for only $3 / 8$ patients $(37 \%)$. All three fulfilled the intraoperative criteria for convincing decompression. Despite our stringent approach, 1 of these 3 patients failed in the UPJO treatment. To put the subject into perspective, only 3/15 (20\%) of our horseshoe kidneys patients were appropriate candidates for Hellstrom alone. Even then, treatment in 1 patient failed (33\%) in our highly selected group. 
Shadpour et al.

Table 3. Comparison of existing case series on laparoscopic pyeloplasty in horseshoe kidneys

\begin{tabular}{|c|c|c|c|c|c|c|c|c|c|c|c|}
\hline \multirow[b]{2}{*}{ Study } & \multirow{2}{*}{$\begin{array}{c}\text { No. } \\
\text { patients }\end{array}$} & \multirow[b]{2}{*}{ Approach } & \multicolumn{5}{|c|}{ Technique for relief of the obstruction } & \multirow[b]{2}{*}{$\begin{array}{c}\text { OR time } \\
(\min )\end{array}$} & \multirow{2}{*}{$\begin{array}{c}\text { Hospital } \\
\text { Stay } \\
\text { (days) }\end{array}$} & \multirow{2}{*}{$\begin{array}{c}\text { Follow } \\
\text { up } \\
\text { (months) }\end{array}$} & \multirow[b]{2}{*}{$\begin{array}{c}\text { Clinical } \\
\text { success \% }\end{array}$} \\
\hline & & & Dismembered & $\begin{array}{l}\text { Foley } \\
\text { YV }\end{array}$ & Scardino & Hellstrom & Isthmectomy & & & & \\
\hline $\begin{array}{l}\text { Chammas } \\
\text { et al. }{ }^{11}\end{array}$ & 3 & $\begin{array}{c}\text { Robotic } \\
\text { trans- } \\
\text { peritoneal }\end{array}$ & $3 / 3$ & - & - & - & $0 / 3$ & $\begin{array}{c}148.3 \\
(125-170)\end{array}$ & $\begin{array}{c}7.2 \\
(6-10)\end{array}$ & $\begin{array}{c}21 \\
(13-29)\end{array}$ & 100 \\
\hline $\begin{array}{l}\text { Faddegon } \\
\text { et al. }{ }^{8}\end{array}$ & 9 & $\begin{array}{c}\text { Robotic } \\
\text { trans- } \\
\text { peritoneal }\end{array}$ & $7 / 9$ & - & - & $2 / 9$ & NA & $\begin{array}{c}136 \\
(109-230)\end{array}$ & $\begin{array}{c}1.5 \\
(1-4)\end{array}$ & $\begin{array}{c}11 \\
(3-45)\end{array}$ & $\begin{array}{c}100 \\
(78 \% \\
\text { imaging) }\end{array}$ \\
\hline $\begin{array}{l}\text { Nishi et } \\
\text { al. }{ }^{4}\end{array}$ & 5 & $\begin{array}{l}\text { Trans } \\
\text { peritoneal } \\
\text { laparo- } \\
\text { scopic }\end{array}$ & $5 / 5$ & - & - & - & $0 / 5$ & $\begin{array}{c}209 \\
(80-264)\end{array}$ & 4.5 & 13 & 100 \\
\hline $\begin{array}{l}\text { Wang et } \\
\text { al. }^{2}\end{array}$ & 8 & $\begin{array}{l}\text { Retro } \\
\text { peritoneal } \\
\text { laparo- } \\
\text { scopic }\end{array}$ & $8 / 8$ & - & - & - & $8 / 8$ & $\begin{array}{c}192 \\
(148-252)\end{array}$ & $\begin{array}{c}5.8 \\
(4-7)\end{array}$ & $\begin{array}{c}45 \\
(18-96)\end{array}$ & 100 \\
\hline $\begin{array}{l}\text { Present } \\
\text { series }\end{array}$ & 15 & $\begin{array}{l}\text { Trans- } \\
\text { peritoneal } \\
\text { laparo- } \\
\text { scopic }\end{array}$ & $8 / 15$ & $2 / 15$ & $1 / 15$ & $3 / 15$ & $1 / 15$ & $\begin{array}{c}129 \\
(90-186)\end{array}$ & $\begin{array}{c}2.8 \\
(1-6)\end{array}$ & $\begin{array}{c}60 \\
(18-120)\end{array}$ & 93.3 \\
\hline
\end{tabular}

In retrospect, the proximal ureter in that particular patient tended to fall back into a memory kink despite rapid detumescence and good peristalsis after translocating the vessel. An indwelling stent was placed to rectify this segment over the course of healing, but the patient ultimately required reoperative laparoscopic dismembered pyeloplasty for persistant obstruction at 7 months. The patient's symptoms worsened and renogram washout curve deteriorated after complete symptomatic relief for the first 6 weeks while stented (Table 2).

This sequence of events was similar to our earlier experience with laparoscopic redo-pyeloplasty patients. ${ }^{14}$ We hypothesized that unilateral urine volume improves, while free flow was guaranteed by postoperative stenting. Once the stent was removed in cases of unresolved obstruction, this enhanced flow continued against persisting obstruction, leading to worsened symptoms and further delayed washout. Other authors have also noted that the washout curve, and not differential function, is the practical index expected to improve in association with resolving symptoms.

In our study, only $1 / 15$ (7\%) of horseshoe kidney with UPJO required isthmectomy. This is in stark contrast to classic surgical teaching ${ }^{7}$ and even to contemporary practices. ${ }^{2}$ However, our findings concur with those found by Nishi and colleagues, ${ }^{4}$ who found no case for isthmectomy in managing 5 patients with hydronephrosis and horseshoe kidneys (Table 3).

Our study is limited by its retrospective nature, but is enhanced by including most surgical techniques in contemporary laparoscopic management of UPJO, its comparatively large sample size, and mean follow-up of up to 10 years.

\section{Conclusion}

To our knowledge, this represents the largest report on laparoscopic pyeloplasty for UPJO in horseshoe kidneys, backed by the longest follow-up to date. Our findings confirm prior reports supporting laparoscopy in this setting, while adding that despite the persuasive prevalence of crossing vessels, transposition alone is seldom sufficient, and patients must be advised on the possibility of additional procedures. We also provide convincing evidence that isthmectomy is by no means inexorable.

Competing interests: The authors declare no competing financial or personal interests.

This paper has been peer-reviewed.

\section{References}

1. Shapiro E, Bauer SB, Chow JS. Anomalies of the upper urinary tract. In: Wein AJ, Kavoussi LR, Novik A, et al. eds. Campbell-Walsh Urology. 10th ed. Philadelphia, PA: Elsevier Saunders; 2012:3123-61. http://dx.doi.org/10.1016/B978-1-4160-6911-9.00117-1

2. Wang $P, X i a D, M a Q$, et al. Retroperitoneal laparoscopic management of ureteropelvic junction obstruction in patients with horseshoe kidney. Urology 2014;84:1351-4. http://dx.doi.org/10.1016/i. urology.2014.07.029

3. Blanc T, Koulouris E, Botto N, et al. Laparoscopic pyeloplasty in children with horseshoe kidney. J Urol 2014;191:1097-103. http://dx.doi.org/10.1016/i.juro.2013.10.059

4. Nishi $M$, Iwamura $M$, Kurosaka $S$, et al. Laparoscopic Anderson-Hynes pyeloplasty without symphysiotomy for hydronephrosis with horseshoe kidney. Asian J Endosc Surg 2013;6:192-6. http://dx.doi. org/10.1111/ases.12038

5. Pe ML, Sterious SN, Liu JB, et al. Robotic dismembered pyeloplasty in a horseshoe kidney after failed endopyelotomy. JSLS 2008;12:210-2. 
6. Shadpour P, Nayyeri RK, Daneshvar R, et al. Prospective clinical trial to compare standard colon-reflecting with transmesocolic laparoscopic pyeloplasty. BJU Int 2012;1 10:1814-8. http://dx.doi.org/10.1111/ j.1464-410X.2012.11081.x

7. Das S, Amar AD. Ureteropelvic junction obstruction with associated renal anomalies. J Urol 1984;131:872 4.

8. Faddegon S, Granberg C, Tan YK, et al. Minimally invasive pyeloplasty in horseshoe kidneys with ureteropelvic junction obstruction: A case series. Int Braz J Urol 2013;39:195-202.

9. Spencer $C D$, Sairam $K$, Challacombe B, et al. Robot-assisted laparoscopic pyeloplasty for the management of pelvi-ureteric junction obstruction in horseshoe kidneys: Initial experience. J Robotic Surg 2009;3:99-102.

10. Nadler RB, Thaxton CS, Kim SC. Hand-assisted laparoscopic pyeloplasty and isthmectomy in a patient with a horseshoe kidney. J Endouro/ 2003;17:909-10. http://dx.doi.org/10.1089/089277903772036262

11. Chammas M Jr, Feuillu B, Coissard A, et al. Laparoscopic robotic-assisted management of pelvi-ureteric junction obstruction in patients with horseshoe kidneys: Technique and 1-year follow-up. BJU Int 2006;97:57983. http://dx.doi.org/10.1111/j.1464-410X.2006.05967.x
12. Meng MV, Stoller ML. Hellström technique revisited: Laparoscopic management of ureteropelvic junction obstruction. Urology 2003;62:404-8; discussion 408-9. http://dx.doi.org/10.1016/S00904295(03)00562-4

13. Simforoosh N, Javaherforooshzadeh A, Aminsharifi A, et al. Laparoscopic management of ureteropelvic junction obstruction in pediatric patients: A new approach to crossing vessels, crossing vein division, and upward transposition of the crossing artery. Pediatr Urol 2010;6:161-5. http://dx.doi.org/10.1016/i. jpurol.2009.07.010

14. Shadpour P, Haghighi R, Maghsoudi R, et al. Laparoscopic redo pyeloplasty after failed open surgery. Urol J 2011;8:31-7.

Correspondence: Dr. Pejman Shadpour, Hasheminejad Kidney Center, Hospital Management Research Center (HMRC), Iran University of Medical Sciences, Tehran, Islamic Republic of Iran; shadpour.p@iums.ac.ir 